\title{
Studien über experimentelles Autohämolysin bei Kaninchen.
}

\author{
Von \\ Shunyo Sunami. \\ (角南春 跲) \\ (Aus der medizinischen Klinil von Prof. T. Kumagai, \\ Tohoku Universität zu Sendai.)
}

\section{Kapitel I.}

Durch Injektion einer Mischung von Lecithin und Schweineserumerzeugtes Autohämolysin

bei Kaninchen.

Versuche, bei Tieren Autohämolysin, das paroxysmale Hämoglobinurie auslöst, experimentell zu erzeugen und dadurch das Wesen dieses Autoantikörpers zu erkennen, sind seit längerer Zeit in unserer Klinik angestellt worden. Nach wiederholten, aber misslungenen Versuchen ist es endlich M. $\mathrm{Namba}$ (i) gelungen, als Erster den Autoantikörper künstlich zu erzeugen, indem er Kaninchen Emulsionen von Organen verschiedener Tiere, vor allem von der Niere des Meerschweinchens injizierte.

Unter Leitung von Prof. ' $\mathrm{T}$. K u magai habe ich diese Untersuchungen fortgesetzt und auch durch Injektion einer Mischung von Lecithin und Schweineserum Autohämolyse hervorrufen können. Über die Resultate dieser Versuche sei im Folgenden Näheres berichtet.

Eine kurze Zusammenfassung dieser Versuche ist schon in der 24ten Versammlung japanischer Internisten im Jahre 1927 mitgeteilt worden. ${ }^{2}$

Methodisches.

Zur Vorbehandlung der Kaninchen gebrauchten wir Lecithin, das mit Alkohol gereinigt und mit Schweineserum vermischt wurde.

$3,7 \mathrm{ccm}$ von $1 \%$ Lecithin (Merck) in Alkohollösung (95\%) werden bis zum Trocknen verdampft; der Rückstand wird mit $1 \mathrm{ccm}$ physiologischer Kochsalzlösung rersetzt und dann mit einem Pistill in einem Mörser chylös gemacht. Der Lösung wird $5 \mathrm{ccm}$ mit physiolo- 
gischer Kochsalzlösung zehnfach verdünnte;, aktives Schweineserum zugesetzt und beides gut rermischt, darauf im Zimmer 30 Minuten lang stehen gelassen.

Das Gemisch injizierten wir normalen Kaninchen intravenös oder intraperitoneal. Den Hämolyse-Versuch in vitro stellten wir nach der von $\mathrm{N} \mathrm{a} \mathrm{m} \mathrm{ba} \mathrm{in} \mathrm{seiner} \mathrm{Arbeit} \mathrm{über} \mathrm{experimentelles} \mathrm{Autohämolysin} \mathrm{angegebenen}$ Methode an.

Das zum Versuch verwendete Serum wurde auf folgende Weise gewonnen. Das aus der Ohrvene des Kaninchens mittels Nadelstichs herabtropfende Blut wurde in ein Reagenzglas aufgefangen und sofort bei $37^{\circ} \mathrm{C}$ in den Brutofen getan. Nachdem Serum und Koagulum sich getrennt hatten, wurde es abzentrifugieri. Auf diese Weise wurde klares Serum ausgeschieden.

Die zum Versuch verwendete Erythrozytenaufschwemmung wurde folgendermassen bereitet. Das aus der Ohrvene des Kaninchens herabtropfende Blut wurde in ein Reagenzglas, das mit einer auf $37^{\circ} \mathrm{C}$ erwïrmten physiologischen Kochsalzlösung gefullt war, aufgefangen und dann abzentrifugiert. Darauf wurde es $z$ wei- oder dreimul mit physiologischer Kochsalzlösung ausgewaschen. Die nach dem Abgiessen zurückbleibende Kochsalzlösung wurde nöglichst gut beseitigt, bis sich eine dicke Emulsion roter Blutkörperchen ergab.

Zur Prüfung der Autohämolyse stellten wir den Kälte-Würme-Versuch an, gleichzeitig als Kontrolle auch den Wärme-Versuch. Der KïlteWärme-Versuch gestaltet sich folgendermassen :

$0,5 \mathrm{~cm}$ aktives Serum und $0,1 \mathrm{ccm}$ Blutzellenemulsion werden im Reagenzglas gemischt, 30 Minuten in Eiswasser unter $3^{\circ} \mathrm{C}$ und dann 2 Stunden in Wasserbad bei $87^{\circ} \mathrm{C}$ gehalten, danach herausgenommen, im Eisschrank stehen gelassen, und nach dem Sinken der roten Blutzellen wird das Resultat abgelesen.

Wärme-Versuch : das obige Serumblutzellengemisch wird ohne rorberige Abkühlung in Wasserbad bei $37^{\circ} \mathrm{C} 2$ Stunden lang gebalten.

Die Autohämolyse wurde nur dann als positiv angesehen, wenn der Würme-Versuch, d. h. die Kontrolle, negativ und der Kälte-Würme-Versuch positiv ausgefallen war.

\section{Versuchsergebnisse.}

Die Ergebnisse der Versuche bei 6 Kaninchen, denen wiederholt Lecithin und Schweineserum eingespritzt waren, sind in Tabelle I übersichtlich mitgeteilt.

Vor der Injeltion wurden die Kaninchen auf etwaige Positivität der Autohämolyse hin geprüft, weil diese Erscheinung gelegentlich bei Kaninchen in normalem Zustand auftritt. Sie war beim Kaninchen Nr. 1 schwach positiv, bei allen übrigen negativ. Nach der ersten Injektion fiel sie bei 5 unter 6 Kaninchen positiv aus. Am 3ten Tag nach der 2ten Injektion war die Autohämolyse vermindert, wie man es ans der 'Tabelle crsieht; die Autohämolyse bei Nr. 1 und 2, die sich darnach verstïrkte, wurde mit der Zeit wieder schwächer; dennoch blieb sie bis zum 33ten Tag 
Autohämolysin bei Kaninchen

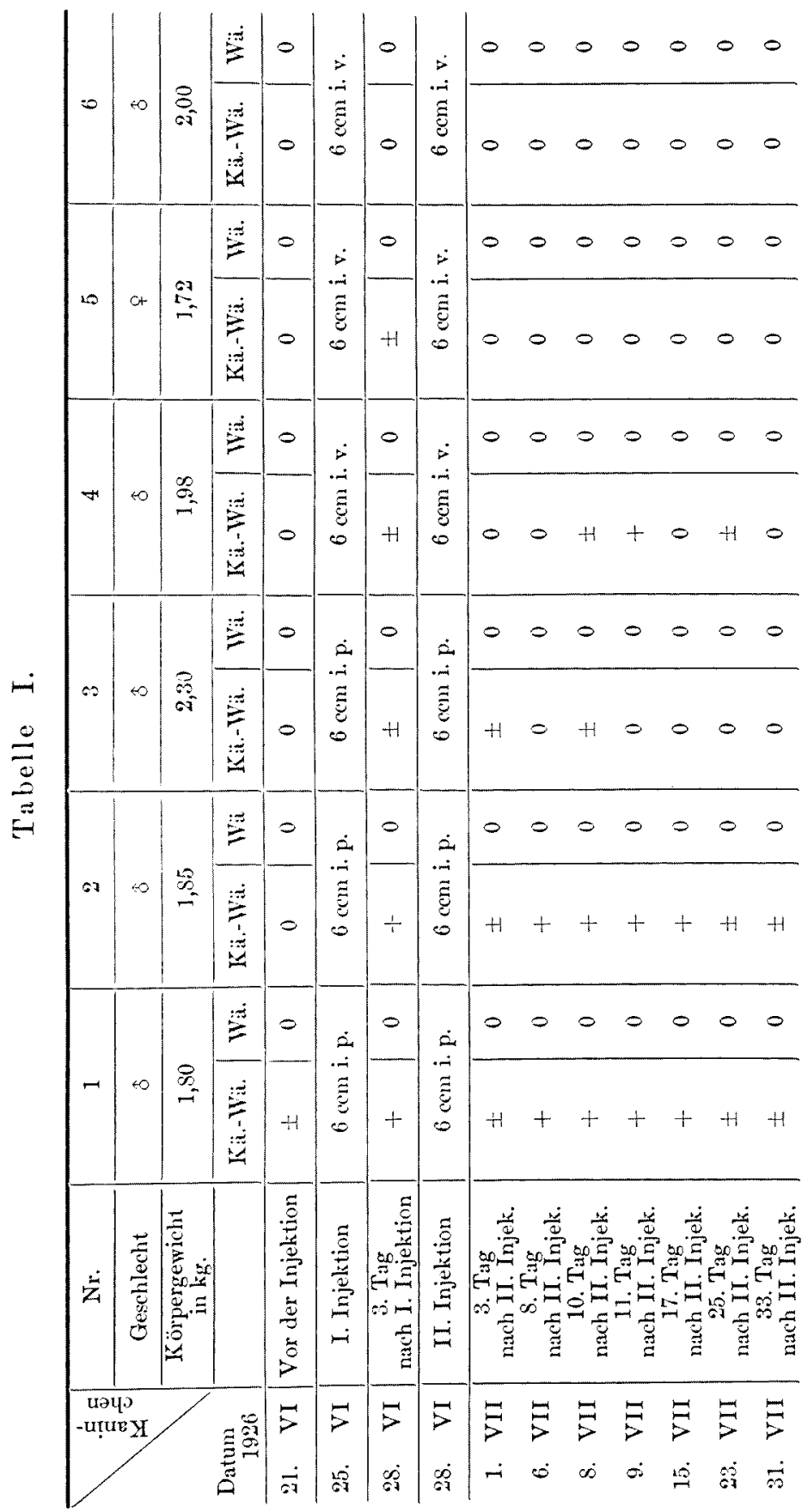




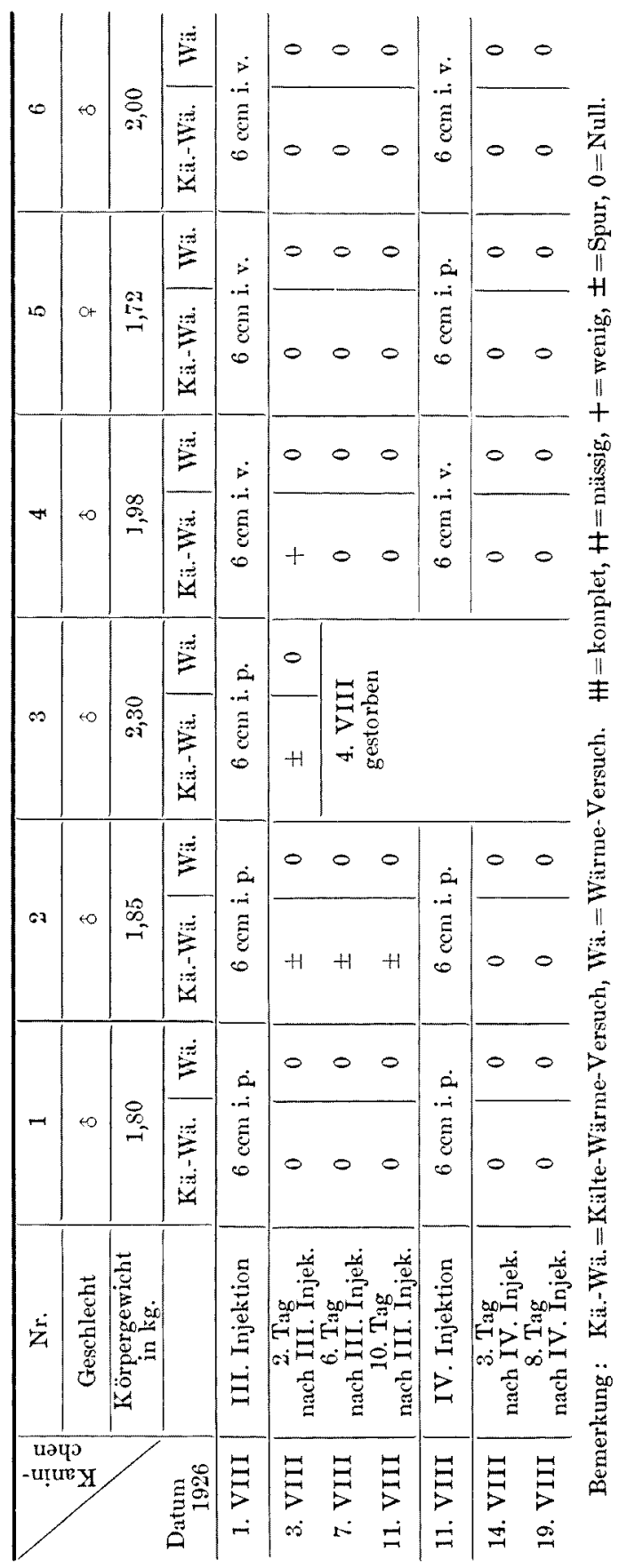

danernd positiv. Bei Nr. 1 wurde das schon vor der Injektion vorhandene Autohämolysin stärker als vor der Injektion. Bei Nr. 4 fiel es erst am 10ten Tag nach der 2ten Injektion positiv aus. Nach der 4ten Injektion war es bei allen Kaninchen ganz negativ. Bei Nr. 6 blieb es trotz 4 maliger Injektion immer negativ.

Über die Beziehungen des durch Injektion erhaltenen Autohämolysins mit der Wassermannschen Reaktion, der Eigenhemmung und dem Heterolysin.

Die Forschungen von $\mathrm{Sach}^{3}$ und mehrerer anderer Autoren haben in nenerer Zeit gezeigt, dass durch Injektion einer Mischung aus Lipoid und Eiweiss bei Kaninchen $W$ assermannsche Reaktion erzeugt werden kann. I to $^{4}$ ) rief bei Kaninchen hochgradige Wassermann- 
Autohämolysin bei Kaninchen

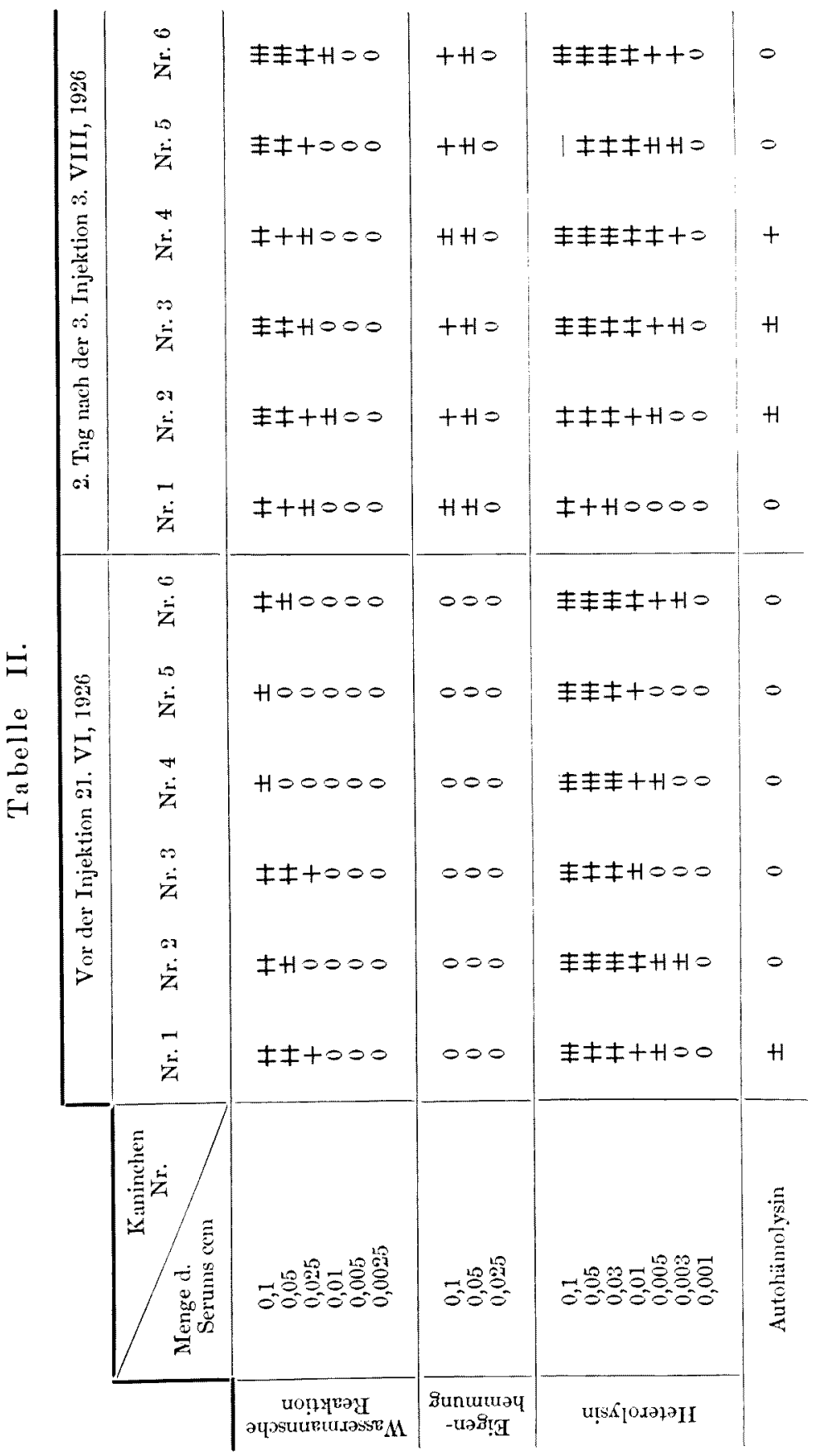


sche Realition dadurch hervor, dass er die Tiere mit der gleichen, von uns gebrauchten Mischung von Lecithin und aktivem Schweineserum behandelte.

$\mathrm{Namba}$ hat über das Verhältnis zwischen der durch Injektion des Forssmanschen Antigens bei Kaninchen erzeugten Wasser mannschen Reaktion und dem dabei auftretenden Autohämolysin berichtet. Danach tritt Autohämolysin, im ganzen genommen, bei Kaninchen mit hochgradiger $W$ asser ma n nscher Reaktion auf; vor allem scheint sie bei schwache Eigenhemmung zeigenden Seren vorzukommen.

Wir untersuchten jedesmal, wenn wir Kaninchen zur Prüfung der Autohämolyse Blut entnahmen, auch ihre Wassermannsche Reaktion, Eigenhemmung und ihr Heterolysin.

Die W asse $r$ m an sche Reaktion und die Eigenhemmung prüften wir nach der von $\mathrm{Namba}$ mitgeteilten Versuchsanordnung und verwendeten das vorher durch Behandlung mit Hammelblut von Heterolysin befreite Serum. Als Antigen diente cholesterinisierter Rinderherzextrakt.

Vor der Injektion war die Wassermanuschen Reaktion schon schwach positiv. Nach der Injektion steigerte sich die Positivitit der Reaktion im allgemeinen, von einigen Schwankungen je nach der Zeit der Prüfung abgesehen. Aber gleichzeitig nahm auch die Eigenhemmung zu.

Nach diesem Versuch lässt sich kaum annehmen, dass ein bestimmtes Verhältnis zwischen der Autohämolyse und der W assermannschen Reaktion, noch auch zwischen der ersteren und der Eigenhemmung besteht.

Heterolysin zeigte einige Schwankungen, je nach der Zeit, aber aus den Versuchsresultaten lässt sich keine Beziehung zur Autohämolyse erkennen. Fin Teil des Protokolls sei in Tabelle II angeführt.

\section{Kapitel II.}

Über Autohämolysin und seine Rezeptoren bei normalen Kaninchen.

Schon 1907 ist von Landsteine $\mathrm{r}^{5)}$ angegeben worden, dass es unter normalen Kaninchen gelegentlich hämolysinhaltige gibt. Wir fanden unter unseren Versuchstieren auch einige derartige.

Zuerst wollten wir die Beziehung dieses praeformiert vorhandenen Autohämolysins zu seinen Rezeptoren der Erythrozyten studieren. Zu dem Zwecke suchten wir einige normale Kaninchen, die hämolysinhaltig waren, aus. Mit diesen Autohämolysinhaltigen und anderen normalen Kaninchen ohne Autohämolysin wurde der folgende Versuch angestellt. 
Versuch 1.

\section{(4. VIII, 1926)}

Normale Kaninchen Nr. A, B, 5', $6^{\prime}$ und $7^{\prime}$ wurden zuerst auf Vorhandensein von Autohämolysin hin geprüft; es ergab sich, dass das Serum des Kaninchens Nr. $6^{\prime}$ auf die eigenen Erythrozyten beim Kälte-WärmeVersuch müssig stark und das des Kaninchens Nr. $5^{\prime}$ ganz spurweise hämolytisch wirkte, während die übrigen Kaninchen $\mathrm{Nr} . \mathrm{A}, \mathrm{B}$ und $7^{\prime}$ gar kein Hämolysin in sich trugen. Es wurden von den Seren und der Erythrozy tenaufschwemmung alle möglichen Kombinationen bereitet, abgekühlt und erwärmt. Zur Kontrolle diente das Serum-Erythrozyten-Gemisch, das ohne vorherige Abkühlung nur erwärmt wurde.

Das Resultat ersieht man aus 'Tabelle III.

Die Tabelle zeigt, dass die Erythrozyten sowohl des Kaninchens Nr. $5^{\prime}$ wie auch des Nr. 6' ron den Seren A, B, 5' und 6' hämolysiert werden. Nur das Serum des Kaninchens Nr. 7 ' wirkt auf keinerlei Erythrozyten hämolytisch. Also haben die Seren von Nr. A, B, 5' und 6' Kältehämolysin, nur das Serum des Kaninchens Nr. 7 ' nicht. Die Erythrozyten von Nr. A, B und $\tau^{\prime}$ haben keine Rezeptoren.

Die Resultate von 3 anderen Versuchen (Versuch 1b, 1c und 1d), die ganz nach derselben Anordnung ausgeführt wurden, sind auch in Tabelle III enthalten.

Aus diesen Versuchen ist zu ersehen, dass die roten Blutkörperchen einer gewissen Art durch die Seren nicht allein der Autohämolyse ergebenden, sondern auch der negative Autohämolyse zeigenden Kaninchen hämolysiert werden : die roten Blutkörperchen anderer Arten werden dagegen durch kein Serum hämolysiert.

Aus diesen Resultaten können folgende Tatsachen erschlossen werden : a. Es gibt bei normalen Kaninchen zwei Sorten von Seren, ambozeptorenhaltige und nicht-ambozeptorenhultige.

b. Gleichfalls gibt es bei Kaninchen zweierlei rote Blutkörperchen, rezeptorenhaltige und nicht-rezeptorenhaltige.

c. Es gibt normale Kaninchen, die alle beide haben. Dies sind die Fialle, bei denen Autchämolyse auftritt.

d. Wenn man rezeptorenhaltige Blutzellen irgend einem ambozeptorenhaltigen Serum zusetzt, so entsteht immer Autohïmolyse.

Aber hin und wieder entsteht ausnahmsweise keine Autohämolyse, wenngleich für rezeptorenhaltig gehaltene rote Blutkörperchen mit dem für 
Tabelle

\begin{tabular}{|c|c|c|c|c|c|}
\hline \multicolumn{3}{|c|}{ Versuch 1 a 4 . VII, 1926} & \multicolumn{3}{|c|}{ Versuch $1 \mathrm{~b} \quad 14$. VII, 1926} \\
\hline \multicolumn{3}{|c|}{$\begin{array}{l}\text { Nr. A, B, } 5^{\prime} 6^{\prime} \text { und } 7^{\prime} \text { waren } \\
\text { normale Kaninchen }\end{array}$} & \multicolumn{3}{|c|}{$\begin{array}{l}\text { Nr. } 7,8,9,10 \text { und } 6^{\prime} \text { waren } \\
\text { normale Kaninchen }\end{array}$} \\
\hline $\begin{array}{l}\text { Aktives } \\
\text { Serum } \\
5 \text { Tropfen }\end{array}$ & $\begin{array}{c}\text { Erythrozyten- } \\
\text { emulsion } \\
1 \text { Tropfen }\end{array}$ & $\begin{array}{l}\text { Kü.-Wü.- } \\
\text { Versuch }\end{array}$ & $\begin{array}{c}\text { Aktives } \\
\text { Serum } \\
5 \text { Tropfen }\end{array}$ & $\begin{array}{c}\text { Erythrozyten- } \\
\text { emulsion } \\
1 \text { Tropfen }\end{array}$ & $\begin{array}{l}\text { Kä.-Wü.- } \\
\text { Versuch }\end{array}$ \\
\hline $\begin{array}{l}\text { A S } \\
\text { A S } \\
\text { A S } \\
\text { A S } \\
\text { A S }\end{array}$ & $\begin{array}{ll}\mathrm{A} & \mathrm{R} \\
\mathrm{B} & \mathrm{R} \\
5^{\prime} & \mathrm{R} \\
6^{\prime} & \mathrm{R} \\
7^{\prime} & \mathrm{R}\end{array}$ & $\begin{array}{l}0 \\
0 \\
\pm \\
\pm \\
0\end{array}$ & $\begin{array}{l}7 \mathrm{~S} \\
7 \mathrm{~S} \\
7 \mathrm{~S} \\
7 \mathrm{~S} \\
7 \mathrm{~S}\end{array}$ & $\begin{array}{r}7 \mathbf{R} \\
8 \mathbf{R} \\
9 \mathbf{R} \\
10 \mathrm{R} \\
6^{\prime} \mathrm{R}\end{array}$ & $\begin{array}{l} \pm ? \\
0 \\
0 \\
0 \\
\pm\end{array}$ \\
\hline $\begin{array}{l}\text { B S } \\
\text { B S } \\
\text { B S } \\
\text { B S } \\
\text { B S }\end{array}$ & $\begin{array}{cc}\mathrm{B} & \mathrm{R} \\
5^{\prime} & \mathrm{R} \\
6^{\prime} & \mathrm{R} \\
7^{\prime} & \mathrm{R} \\
\mathrm{A} & \mathrm{R}\end{array}$ & $\begin{array}{l}0 \\
+ \\
+ \\
0 \\
0\end{array}$ & $\begin{array}{l}8 \mathrm{~S} \\
8 \mathrm{~S} \\
8 \mathrm{~S} \\
8 \mathrm{~S} \\
8 \mathrm{~S}\end{array}$ & $\begin{array}{rl}8 & R \\
9 & R \\
10 & R \\
6^{\prime} & R \\
7 & R\end{array}$ & $\begin{array}{l}0 \\
0 \\
\pm ? \\
+ \\
0\end{array}$ \\
\hline $\begin{array}{l}5^{\prime} \mathrm{S} \\
5^{\prime} \mathrm{S} \\
5^{\prime} \mathrm{S} \\
5^{\prime} \mathrm{S} \\
5^{\prime} \mathrm{S}\end{array}$ & $\begin{array}{ll}5^{\prime} & \mathrm{R} \\
6^{\prime} & \mathrm{R} \\
7^{\prime} & \mathrm{R} \\
\mathrm{A} & \mathrm{R} \\
\mathrm{B} & \mathrm{R}\end{array}$ & $\begin{array}{l} \pm \\
+ \\
0 \\
0 \\
0\end{array}$ & $\begin{array}{l}9 \mathrm{~S} \\
9 \mathrm{~S} \\
9 \mathrm{~S} \\
9 \mathrm{~S} \\
9 \mathrm{~S}\end{array}$ & $\begin{array}{rl}9 \mathrm{R} \\
10 \mathrm{R} \\
6^{\prime} & \mathrm{R} \\
7 & \mathrm{R} \\
8 & \mathrm{R}\end{array}$ & $\begin{array}{l}0 \\
0 \\
0 \\
\pm ? \\
0\end{array}$ \\
\hline $\begin{array}{l}6^{\prime} \mathrm{S} \\
6^{\prime} \mathrm{S} \\
6^{\prime} \mathrm{S} \\
6^{\prime} \mathrm{S} \\
6^{\prime} \mathrm{S}\end{array}$ & $\begin{array}{cc}6^{\prime} & \mathrm{R} \\
7^{\prime} & \mathrm{R} \\
\mathrm{A} & \mathrm{R} \\
\mathrm{B} & \mathrm{R} \\
5^{\prime} & \mathrm{R}\end{array}$ & $\begin{array}{l}+ \\
0 \\
0 \\
0 \\
+\end{array}$ & $\begin{array}{l}10 \mathrm{~s} \\
10 \mathrm{~S} \\
10 \mathrm{~S} \\
10 \mathrm{~S} \\
10 \mathrm{~s}\end{array}$ & $\begin{aligned} 10 \mathrm{R} \\
6^{\prime} \mathrm{R} \\
7 \mathrm{R} \\
8 \mathrm{R} \\
9 \mathrm{R}\end{aligned}$ & $\begin{array}{l}0 \\
\pm \\
\pm \\
0 \\
0\end{array}$ \\
\hline $\begin{array}{l}7^{\prime} \mathrm{S} \\
7^{\prime} \mathrm{S} \\
7^{\prime} \mathrm{S} \\
7^{\prime} \mathrm{S} \\
7^{\prime} \mathrm{S}\end{array}$ & $\begin{array}{cc}7^{\prime} & \mathrm{R} \\
\mathrm{A} & \mathrm{R} \\
\mathrm{B} & \mathrm{R} \\
5^{\prime} & \mathrm{R} \\
6^{\prime} & \mathrm{R}\end{array}$ & $\begin{array}{l}0 \\
0 \\
0 \\
0 \\
0\end{array}$ & $\begin{array}{l}6^{\prime} \mathrm{S} \\
6^{\prime} \mathrm{S} \\
6^{\prime} \mathrm{S} \\
6^{\prime} \mathrm{S} \\
6^{\prime} \mathrm{S}\end{array}$ & $\begin{array}{rl}6^{\prime} & R \\
7 & R \\
8 & R \\
9 & R \\
10 & R\end{array}$ & $\begin{array}{l}+ \\
0 \\
0 \\
0 \\
0\end{array}$ \\
\hline
\end{tabular}

Bemerkung: $S$ und $R$ neben den Schriftzeichen bedeuten respektiv aktives Serum und Frythrozytenemulsion.

Der zur Kontrolle gediente Wärme-Versuch war bei jedem SerumErythrozyten-Gemisch negativ. 
III.

\begin{tabular}{|c|c|c|c|c|c|}
\hline \multicolumn{3}{|c|}{ Versuch 1 c 16. VII, 1926} & \multicolumn{3}{|c|}{ Versuch $1 \mathrm{~d} \quad 19 . \mathrm{VII}, 1926$} \\
\hline \multicolumn{3}{|c|}{$\begin{array}{l}\text { Nr. } 11,12,13,14,15,6^{\prime} \text { und } B \\
\text { waren normale } \mathrm{K} \text { aninchen. }\end{array}$} & \multicolumn{3}{|c|}{$\begin{array}{l}\text { Nr. } 16,17,18,19,20 \mathrm{~B} \text { und } 6^{\prime} \\
\text { waren normale Kaninchen }\end{array}$} \\
\hline $\begin{array}{l}\text { Aktives } \\
\text { Serun } \\
5 \text { Tropfen }\end{array}$ & $\begin{array}{c}\text { Erythrozyten- } \\
\text { enulsion } \\
1 \text { Tropfen }\end{array}$ & $\begin{array}{l}\text { Kï-Wi:- } \\
\text { Versuch }\end{array}$ & $\begin{array}{l}\text { Aktives } \\
\text { Serum } \\
5 \text { Tropfen }\end{array}$ & $\begin{array}{c}\text { Erythrozyten- } \\
\text { emulsion } \\
1 \text { Tropfen }\end{array}$ & $\begin{array}{l}\text { Kä.-Wa.- } \\
\text { Versuch }\end{array}$ \\
\hline $11 \mathrm{~S}$ & $11 \mathrm{R}$ & 0 & $16 \mathrm{~S}$ & $16 \mathrm{R}$ & 0 \\
\hline $11 \mathrm{~S}$ & $12 \mathrm{R}$ & 0 & $16 \mathrm{~S}$ & $17 \mathrm{R}$ & 0 \\
\hline $11 \mathrm{~S}$ & $13 \mathrm{R}$ & 0 & $16 \mathrm{~S}$ & $18 \mathrm{R}$ & 0 \\
\hline $11 \mathrm{~S}$ & $14 \mathrm{R}$ & 0 & $16 \mathrm{~S}$ & $19 \mathrm{R}$ & 0 \\
\hline $11 \mathrm{~S}$ & $15 \mathrm{R}$ & 0 & $16 \mathrm{~s}$ & $20 \mathrm{R}$ & + \\
\hline $11 \mathrm{~S}$ & $6^{\prime} \mathrm{R}$ & 0 & $16 \mathrm{~S}$ & B R & 0 \\
\hline $11 \mathrm{~S}$ & B R & 0 & $16 \mathrm{~S}$ & $6^{\prime} \mathrm{R}$ & \pm \\
\hline $12 \mathrm{~S}$ & $12 \mathrm{R}$ & 0 & $17 \mathrm{~S}$ & $17 \mathrm{R}$ & 0 \\
\hline $12 \mathrm{~S}$ & $13 \mathrm{R}$ & 0 & $17 \mathrm{~S}$ & $18 \mathrm{R}$ & 0 \\
\hline $12 \mathrm{~S}$ & $14 \mathrm{R}$ & 0 & $17 \mathrm{~S}$ & $19 \mathrm{R}$ & 0 \\
\hline $12 \mathrm{~S}$ & $15 \mathrm{R}$ & 0 & $17 \mathrm{~s}$ & $20 R$ & + \\
\hline $12 \mathrm{~S}$ & $6^{\prime} \mathrm{R}$ & 0 & $17 \mathrm{~S}$ & $B R$ & 0 \\
\hline $12 \mathrm{~S}$ & $\mathrm{~B} R$ & 0 & $17 \mathrm{~S}$ & $6^{\prime} \mathrm{R}$ & \pm \\
\hline $12 \mathrm{~s}$ & $11 R$ & 0 & $17 \mathrm{~S}$ & $16 \mathrm{R}$ & 0 \\
\hline $13 \mathrm{~S}$ & $13 \mathrm{R}$ & 0 & $18 \mathrm{~S}$ & $18 \mathrm{R}$ & 0 \\
\hline $13 \mathrm{~S}$ & $14 \mathrm{R}$ & 0 & $18 \mathrm{~S}$ & $19 \mathrm{R}$ & 0 \\
\hline $13 \mathrm{~S}$ & $15 \mathrm{R}$ & \pm & $18 \mathrm{~S}$ & $20 \mathrm{R}$ & + \\
\hline $13 \mathrm{~S}$ & $6^{\prime} \mathrm{R}$ & 0 & $18 \mathrm{~S}$ & B R & 0 \\
\hline $13 \mathrm{~S}$ & B R & \pm & $18 \mathrm{~s}$ & $6^{\prime} \mathrm{R}$ & \pm \\
\hline $13 \mathrm{~S}$ & $11 \mathrm{R}$ & $\pm ?$ & $18 \mathrm{~S}$ & $16 R$ & 0 \\
\hline $13 \mathrm{~S}$ & $12 \mathrm{R}$ & 0 & $18 \mathrm{~s}$ & $17 \mathrm{R}$ & \pm \\
\hline $14 \mathrm{~S}$ & $14 \mathbf{R}$ & 0 & $19 \mathrm{~S}$ & $19 R$ & 0 \\
\hline $14 \mathrm{~S}$ & $15 \mathrm{R}$ & 0 & $19 \mathrm{~S}$ & $20 R$ & 0 \\
\hline $14 \mathrm{~S}$ & $6^{\prime} \mathrm{R}$ & 0 & $19 \mathrm{~S}$ & $B R$ & 0 \\
\hline $14 \mathrm{~S}$ & $\mathrm{BR}$ & 0 & $19 \mathrm{~S}$ & $6^{\prime} \mathrm{R}$ & 0 \\
\hline $14 \mathrm{~S}$ & $11 \mathrm{R}$ & 0 & $19 \mathrm{~S}$ & $16 \mathrm{R}$ & 0 \\
\hline $14 \mathrm{~S}$ & $12 \mathrm{R}$ & 0 & $19 \mathrm{~S}$ & $17 \mathrm{R}$ & 0 \\
\hline $14 \mathrm{~S}$ & $13 \mathrm{R}$ & 0 & $19 \mathrm{~S}$ & $18 \mathrm{R}$ & 0 \\
\hline $15 \mathrm{~S}$ & $15 \mathrm{R}$ & 0 & $20 \mathrm{~S}$ & $20 \mathrm{R}$ & 0 \\
\hline $15 \mathrm{~S}$ & $6^{\prime} \mathrm{R}$ & 0 & $20 \mathrm{~S}$ & B R & 0 \\
\hline $15 \mathrm{~S}$ & $\mathrm{BR}$ & 0 & $20 \mathrm{~S}$ & $6^{\prime} R$ & 0 \\
\hline $15 \mathrm{~S}$ & $11 \mathrm{P}$ & 0 & $20 \mathrm{~S}$ & $16 \mathrm{R}$ & 0 \\
\hline $15 \mathrm{~S}$ & $12 \mathrm{R}$ & 0 & $20 \mathrm{~S}$ & $17 \mathrm{R}$ & \pm \\
\hline $15 \mathrm{~S}$ & $13 \mathrm{R}$ & 0 & $20 \mathrm{~S}$ & $18 \mathrm{R}$ & 0 \\
\hline $15 \mathrm{~S}$ & $14 \mathrm{R}$ & 0 & $20 \mathrm{~S}$ & $19 \mathrm{R}$ & 0 \\
\hline $6^{\prime} \mathrm{S}$ & $6^{\prime} \mathbf{R}$ & + & $\mathrm{BS}$ & $\mathrm{BR}$ & \pm \\
\hline $6^{\prime} \mathrm{S}$ & B R & 0 & $\mathrm{BS}$ & $6^{\prime} \mathrm{R}$ & \pm \\
\hline $6^{\prime} \mathrm{S}$ & $11 \mathrm{R}$ & 0 & $\mathrm{BS}$ & $16 \mathrm{R}$ & 0 \\
\hline $6^{\prime} \mathrm{S}$ & $12 \mathrm{R}$ & 0 & BS & $17 \mathrm{R}$ & \pm \\
\hline $6^{\prime} \mathrm{S}$ & $13 \mathrm{R}$ & + & BS & $18 \mathrm{R}$ & 0 \\
\hline $6^{\prime} \mathrm{S}$ & $14 \mathrm{P}$ & 0 & BS & $19 \mathrm{R}$ & 0 \\
\hline $6^{\prime} \mathrm{s}$ & $15 \mathrm{R}$ & + & $\mathrm{BS}$ & $20 R$ & \pm \\
\hline $\mathrm{BS}$ & $\mathrm{B} R$ & 0 & $6^{\prime} \mathrm{S}$ & $6^{\prime} R$ & + \\
\hline $\mathrm{BS}$ & $11 \mathrm{R}$ & 0 & $6^{\prime} \mathrm{S}$ & $16 R$ & 0 \\
\hline BS & $12 \mathrm{R}$ & 0 & $6^{\prime} \mathrm{S}$ & $17 \mathrm{R}$ & $\Rightarrow$ \\
\hline B S & $13 \mathrm{R}$ & + & $6^{\prime} \mathrm{S}$ & $18 \mathrm{R}$ & \pm \\
\hline B S & $14 \mathrm{P}$ & 0 & $6^{\prime} \mathrm{S}$ & $19 \mathrm{R}$ & 0 \\
\hline B S & $15 \mathrm{R}$ & $\pm ?$ & $6^{\prime} \mathrm{S}$ & $20 \mathrm{R}$ & + \\
\hline $\mathrm{B} S$ & $6^{\prime} \mathrm{R}$ & \pm & $6^{\prime} \mathrm{S}$ & $\mathrm{BP}$ & 0 \\
\hline
\end{tabular}


ambozeptorenhaltig gehaltenen Serum zusammengebracht werden. Aus diesen Versuchen ergibt sich nicht klar, ob diese Erscheinung dem Mengenverhältnis zwischen beiden oder einer anderen Ursache zuzuschreiben ist. Jedenfalls ist es eine sehr seltene Ausnahme.

\section{Kapitel III.}

Uber die Rezeptoren für experimentell erzeugtes Autohämolysin des Kaninchenbluts.

Bei dem bisherigen Studium der Autohämolyse ist hauptsiächlich die Veränderung des Serums erforscht worden. Für die Autohämolyse des menschlichen Bluts wird es als gleichgültig angesehen, welche Erythrozyten man verwendet, abgesehen von isolysinhaltigen. K. I to ${ }^{6}$ in Okayama fand, dass die Autohämolyse eine gewisse Beziehung zur Blutgruppe hat: nämlich das hämolytische Agens im Serum übt seine Wirkung am stärksten auf die den Rezeptor A tragenden Blutkörperchen der Gruppe II und IV aus, aber viel schwächer anf die den Rezeptor B tragenden Blutkörperchen der Gruppe I und III ; es scheint also bis zu einem gewissen Grade eine spezifische Angreifbarkeit der gesunden Menschenblutkörperchen zu bestehen. Bei einem ähnlichen Versuche fand jedoch Witebsky, ${ }^{7}$ dass die Blntgruppe nichts mit der Autobämolyse zu tun habe. Unsere diesbezüglichen Versuche haben anch noch zu keinem eindeutigen Resultate geführt.

Ein ähnliches Verhältnis fiel uns schon seit langer Zeit bei dem von uns experimentell erzeugten Autohämolysin des Kaninchens auf. Die Hämolyse durch dieses Hämolysin ist niemals komplett ; die ungelöst gebliebenen roten Blutkörperchen lassen sich durch Zusatz frischen, hämolysinhaltigen Serums garnicht auflösen. Daraus ersieht man, dass die Erythrozyten des Kaninchens nur zum Teil mit Rezeptoren für Autohämolysin versehen sind. Es gibt, wie in Kapitel II mitgeteilt, zwei Arten normaler Kaninchen, rezeptorenhaltige und nicht-rezeptorenhaltige.

Um das Verhältnis bei den Kaninchen mit experimentell erzeugtem Autohämolysin genau zu erkennen, stellten wir den nachstehenden Versuch mit injizierten Kaninchen an.

\section{Versuch 2.}

(8. VII, 1926)

Zu dem Zweck wurden 6 Kaninchen mit Mischung von Lecithin und Schweineserum injiziert. Nach der Injektion wurde das Blut entnommen. 
Ausserdem wurden 2 nicht behandelte Kraninchen $\left(6^{\prime}\right.$ und B) für den Versuch genommen. Von diesen Seren und Erythrozyten wurden alle möglicheu Kombinationen hergestellt und dem Kälte-Wärme-Versuch unterworfen. Das Resultat dieses Versuches ist in Tabelle IV wiedergegeben.

Tabelle IV.

\begin{tabular}{|c|c|c|c|c|c|}
\hline $\begin{array}{l}\text { Aktives } \\
\text { Serum } \\
5 \text { Tropfen }\end{array}$ & $\begin{array}{l}\text { Erythrozyten- } \\
\text { emulsion } \\
1 \text { Tropfen }\end{array}$ & $\begin{array}{l}\mathrm{Kai}-\mathrm{W} \text { i. } \\
\text { Versuch }\end{array}$ & $\begin{array}{l}\text { Aktives } \\
\text { Serum } \\
5 \text { Tropfen }\end{array}$ & $\begin{array}{l}\text { Erythrozyten- } \\
\text { emulsion } \\
1 \text { Tropfen }\end{array}$ & $\begin{array}{l}\text { Kä.-Wi.- } \\
\text { Versuch }\end{array}$ \\
\hline $\begin{array}{l}1 \mathrm{~S} \\
1 \mathrm{~S} \\
1 \mathrm{~S} \\
1 \mathrm{~S} \\
1 \mathrm{~S} \\
1 \mathrm{~S} \\
1 \mathrm{~S} \\
1 \mathrm{~S}\end{array}$ & $\begin{array}{rl}1 & R \\
2 & R \\
3 & R \\
4 & R \\
5 & R \\
6 R \\
6^{\prime} \mathrm{R} \\
\mathrm{B} R\end{array}$ & $\begin{array}{l}+ \\
+ \\
+ \\
+ \\
\pm \\
0 \\
+ \\
\pm ?\end{array}$ & $\begin{array}{l}5 \mathrm{~S} \\
5 \mathrm{~S} \\
5 \mathrm{~S} \\
5 \mathrm{~S} \\
5 \mathrm{~S} \\
5 \mathrm{~S} \\
5 \mathrm{~S} \\
5 \mathrm{~S}\end{array}$ & $\begin{array}{r}5 \mathrm{R} \\
6 \mathrm{R} \\
6^{\prime} \mathrm{R} \\
\mathrm{B} \mathrm{R} \\
1 \mathrm{R} \\
2 \mathrm{R} \\
3 \mathrm{R} \\
4 \mathrm{R}\end{array}$ & $\begin{array}{l}0 \\
0 \\
+ \\
0 \\
+ \\
+ \\
+ \\
\pm\end{array}$ \\
\hline $\begin{array}{l}2 \mathrm{~S} \\
2 \mathrm{~S} \\
2 \mathrm{~S} \\
2 \mathrm{~S} \\
2 \mathrm{~S} \\
2 \mathrm{~S} \\
2 \mathrm{~S} \\
2 \mathrm{~S}\end{array}$ & $\begin{array}{rr}2 \mathrm{R} \\
3 \mathrm{R} \\
4 \mathrm{R} \\
5 \mathrm{R} \\
6 \mathrm{R} \\
6^{\prime} \mathrm{R} \\
\mathrm{B} \\
1 \mathrm{R} \\
1 \mathrm{R}\end{array}$ & $\begin{array}{l}+ \\
+ \\
\pm \\
0 \\
0 \\
+ \\
0 \\
+\end{array}$ & $\begin{array}{l}6 \mathrm{~S} \\
6 \mathrm{~S} \\
6 \mathrm{~S} \\
6 \mathrm{~S} \\
6 \mathrm{~S} \\
6 \mathrm{~S} \\
6 \mathrm{~S} \\
6 \mathrm{~S}\end{array}$ & $\begin{array}{rl}6 & \mathrm{R} \\
6^{\prime} & \mathrm{R} \\
\mathrm{B} & \mathrm{R} \\
1 & \mathrm{R} \\
2 & \mathrm{R} \\
3 & \mathrm{R} \\
4 & \mathrm{R} \\
5 & \mathrm{R}\end{array}$ & $\begin{array}{l}0 \\
+ \\
0 \\
+ \\
+ \\
+ \\
0 \\
0\end{array}$ \\
\hline $\begin{array}{l}3 \mathrm{~S} \\
3 \mathrm{~S} \\
3 \mathrm{~S} \\
3 \mathrm{~S} \\
3 \mathrm{~S} \\
3 \mathrm{~S} \\
3 \mathrm{~S} \\
3 \mathrm{~S}\end{array}$ & $\begin{array}{rl}3 & \mathrm{R} \\
4 & \mathrm{R} \\
5 & \mathrm{R} \\
6 & \mathrm{R} \\
6^{\prime} & \mathrm{R} \\
\mathrm{B} & \mathrm{R} \\
1 & \mathrm{R} \\
2 \mathrm{R}\end{array}$ & $\begin{array}{l} \pm \\
0 \\
0 \\
0 \\
\pm \\
0 \\
0 \\
\pm\end{array}$ & $\begin{array}{l}6^{\prime} \mathrm{S} \\
6^{\prime} \mathrm{S} \\
6^{\prime} \mathrm{S} \\
6^{\prime} \mathrm{S} \\
6^{\prime} \mathrm{S} \\
6^{\prime} \mathrm{S} \\
6^{\prime} \mathrm{S} \\
6^{\prime} \mathrm{S}\end{array}$ & $\begin{array}{l}6^{\prime} \mathrm{R} \\
\mathrm{B} \mathrm{R} \\
1 \mathrm{R} \\
2 \mathrm{R} \\
3 \mathrm{R} \\
4 \mathrm{R} \\
5 \mathrm{R} \\
6 \mathrm{R}\end{array}$ & $\begin{array}{l}+ \\
\pm \\
+ \\
+ \\
+ \\
+ \\
\pm \\
0\end{array}$ \\
\hline $\begin{array}{l}4 \mathrm{~S} \\
4 \mathrm{~S} \\
4 \mathrm{~S} \\
4 \mathrm{~S} \\
4 \mathrm{~S} \\
4 \mathrm{~S} \\
4 \mathrm{~S} \\
4 \mathrm{~S}\end{array}$ & $\begin{array}{rl}4 & \mathrm{R} \\
5 \mathrm{R} \\
6 \mathrm{R} \\
6^{\prime} \mathrm{R} \\
\mathrm{B} \mathrm{R} \\
1 \mathrm{R} \\
2 \mathrm{R} \\
3 \mathrm{R}\end{array}$ & $\begin{array}{l} \pm \\
\pm ? \\
\pm \\
+ \\
0 \\
+ \\
+ \\
+\end{array}$ & $\begin{array}{l}\text { BS } \\
\text { BS } \\
B S \\
B S \\
B S \\
B S \\
\text { BS } \\
B S\end{array}$ & $\begin{array}{r}\mathrm{B} \mathrm{R} \\
1 \mathrm{R} \\
2 \mathrm{R} \\
3 \mathrm{R} \\
4 \mathrm{R} \\
5 \mathrm{R} \\
6 \mathrm{R} \\
6^{\prime} \mathrm{R}\end{array}$ & $\begin{array}{l}0 \\
+ \\
+ \\
+ \\
+ \\
0 \\
0 \\
+\end{array}$ \\
\hline
\end{tabular}

Bemerkung: Der zur Kontrolle gediente Wärme-Versuch war bei jedem SerumErythrozyten-Gemisch negativ. Aus der Tabelle ersichtlich, hatten die roten Blutzellen von Nr. 6 keinen Rezeptor.

Wie aus der Tabelle ersichtlich, fällt die Autohämolyse mit einer gewissen Art von roten Blutzellen negativ aus, obwohl ein Serum mit reich- 
lichem Ambozeptorgehalt darauf einwirkt. Diese Erscheinung ist nur dann möglich, wenn man bei einzelnen Blutzellen Mangel an Rezeptoren annimmt; also sieht man, dass es anch bei injizierten Kaninchen solche gibt, die im Blute Rezeptoren haben und sulche, die sie nicht haben.

Im Jahre 1912 berichtete M. Bü rge $\mathbf{r}^{s)}$ über eine Patientin mit Anämie, deren Serum beim Kälte-Wärme-Versuch die eigenen roten Blutzellen durchaus nicht, wohl aber die Blutzellen vieler anderer Patienten aufzulösen vermorhte. Dieses Phänomen beim Menschenblut ist unserem Befunde beim Tiere völlig analog, wenn wir selbst auch beim Menschen niemals einen solchen Fall angetroffen haben. In diesem Fall ist es höchstwahrscheinlich, dass das Blut der Patientin Autohämolysin besass, aber ihm Rezeptoren fehlten, weswegen dasselbe Serum rezeptorenhaltige Blutzellen anderer Kranken aufzulösen imstande war.

\section{Kapitel IV. \\ Über den Mechanismus der experimentellen Auto- hämolyse.}

Wir haben im oben mitgeteilten Versuch über die Ambozeptron und die Rezeptoren sowohl behandelter wie auch normaler Kaninchen berichtet. Nun müssen wir uns die Frage vorlegen, ob beim Auftreten experimenteller Autohämolyse das die Erscheinung hervorrufende Agens in dem Serum oder den

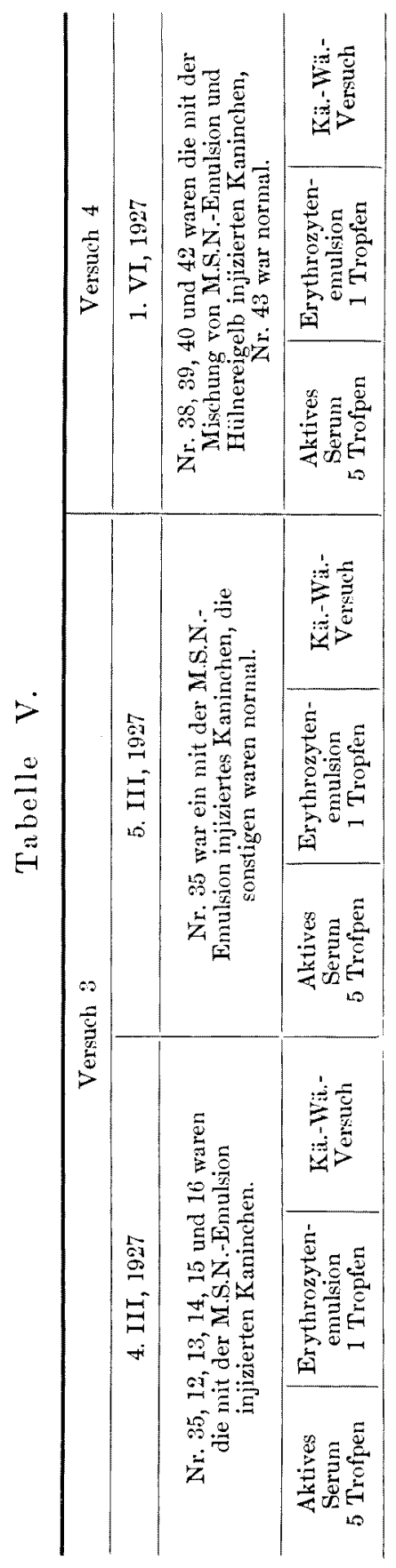


Autohämolysin bei Kaninchen

\begin{tabular}{|c|c|c|c|c|c|}
\hline 00000 & to t+ & $00+t 0$ & $0+t+0$ & to000 & 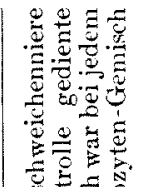 \\
\hline 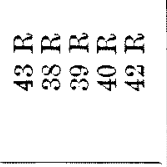 & 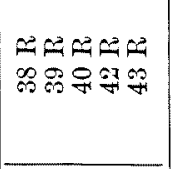 & 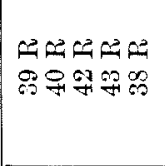 & 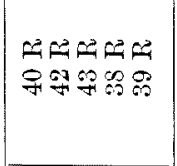 & 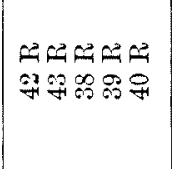 & 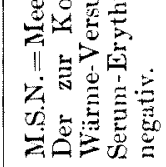 \\
\hline 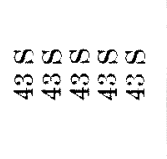 & 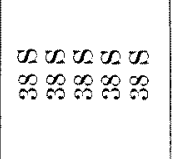 & 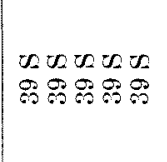 & 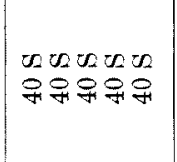 & 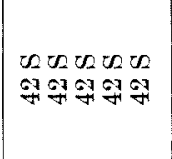 & 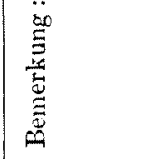 \\
\hline$+0+H+H+$ & $0+H+++$ & 1000000 & 1000000 & $0 H 0000$ & $H+400$ \\
\hline 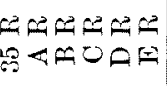 & 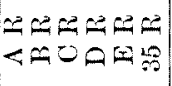 & 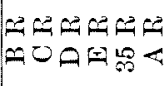 & 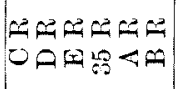 & 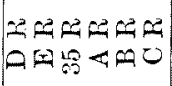 & 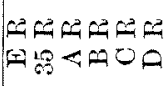 \\
\hline & & & & & \\
\hline
\end{tabular}

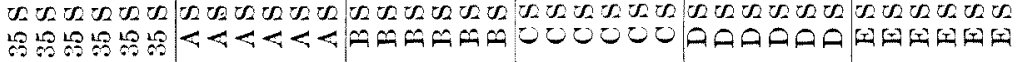

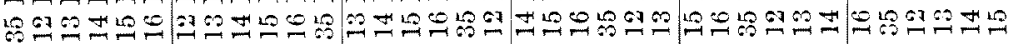

$+H 0=00\left|H=H+H=\frac{1}{H}=\tilde{H} 0000\right| 000+0000+0000+00+10$ 
roten Blutzellen oder in den beiden existiert. Mit anderen Worten : entsteht die Autohämolyse dadurch,

1. dass bei dem physiologisch rezeptorenhaltigen Kaninchen durch die Injektion Autohämolysin im Serum erzeugt wird ? oder dadurch,

2. dass bei dem physiologisch ambozeptorenhaltigen Kaninchen durch die Injektion die Rezeptoren der Blutkörperchen erzeugt werden? oder dadurch,

3. dass durch die Injektion alle beide erzeugt werden ?

Um diese Frage zu lösen, stellten wir die folgende Versuchsreihe an.

\section{Versuch 3.}

Das Serum und die roten Blutzellen eines Autohämolyse ergebenden Kaninchens wurden mit den Seren und Blutzellen von zwei Reihen injizierter und normaler Kaninchen so zusammengebracht, wie Tabelle V zeigen, und an den Kombinationen wurde der Kälte-Wärme-Versuch angestellt. Wie aus der Tabelle $\mathrm{V}$ ersichtlich, wurden die roten Blutzellen von Nr. 35 von den Seren fast aller injizierter Kaninchen (Nr. 13 ausgenommen) aufgelöst, dagegen von denen fast aller normaler Kaninchen (Nr. A ausgenommen) nicht.

Die Beobachtung zeigt, dass durch die Injektion Ambozeptoren erzeugt werden, und dass das Versagen der Autohämolyse beim Versuch auf den Mangel an Rezeptoren der roten Blutzellen zurückzuführen ist, aber freilich ist die Menge der erzeugten Ambozeptoren je nach den Kaninchen bald grösser, bald kleiner.

\section{Versuch 4.}

Die Seren und die roten Blutzellen von einem keine Autohümolyse zeigenden normalen Kaninchen und vier injizierten Kaninchen wurden kombiniert, und an den Kombinationen wurde der Kälte-Wärme-Versuch angestellt.

Beim Versuch 4, dessen Resultat auch in der Tabelle V mitgeteilt ist, ist $\mathrm{Nr} .43$ ein normales Kaninchen, $\mathrm{Nr} .38,39,40$ und 42 sind die mit einem Gemisch 10\%iger Meerschweinchennierenenulsion und Hühnereigelb behandelten.

Dieses Injektionsmaterial wurde derart bereitet, dass Mecrschweinchennierenemulsion und Hühnereigelb im Verhältnis von 10:1 gemischt und gut geschüttelt, sodann durch ein 'Tuch filtriert wurden. $10 \mathrm{ccm}$ davon pro Kilogramm Tiergewicht wurden intravenös eingespritzt. 
Autohämolysin bei Kaninchen

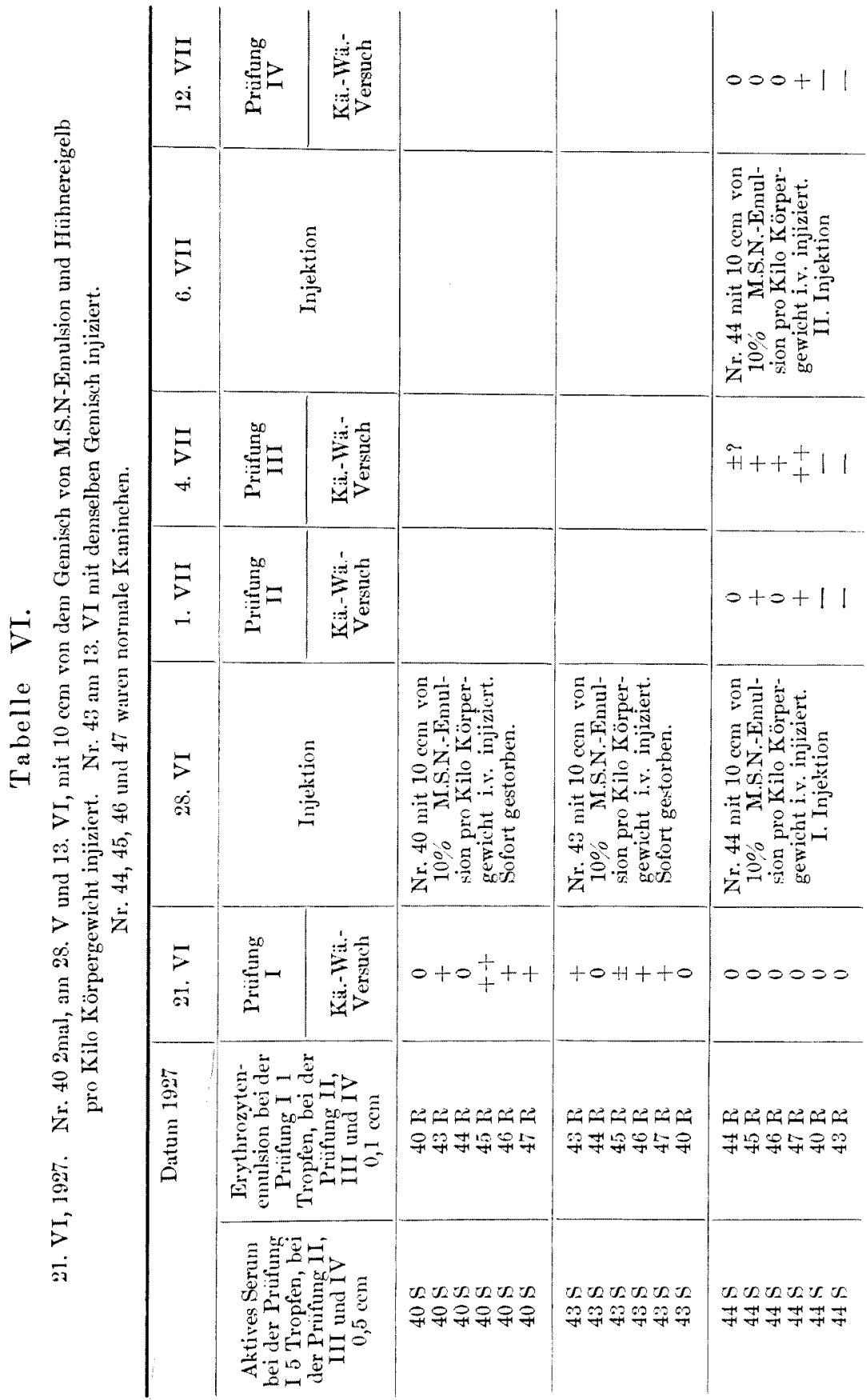




\begin{tabular}{|c|c|c|c|c|c|}
\hline $\begin{array}{l}F \\
5 \\
\substack{9 \\
-j}\end{array}$ & 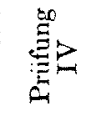 & 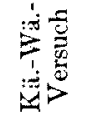 & to +110 & $0+1100$ & +11000 \\
\hline 5 & \multicolumn{2}{|c|}{ 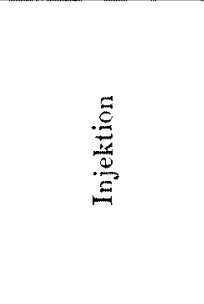 } & 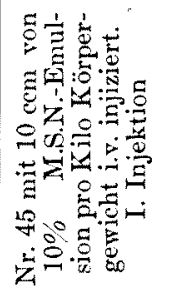 & 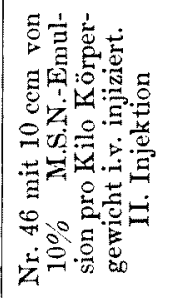 & 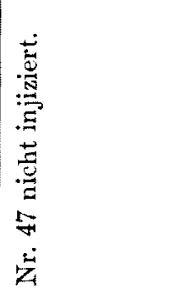 \\
\hline 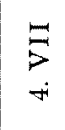 & 影 & 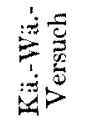 & $+0_{+1}^{+} 10$ & $0+110+1$ & $\stackrel{+}{+} 11++\frac{a}{+}$ \\
\hline 5 & 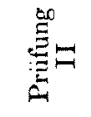 & 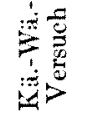 & $+0+110$ & $10+1100$ & $+110+0$ \\
\hline $\overrightarrow{5}$ & \multicolumn{2}{|c|}{ 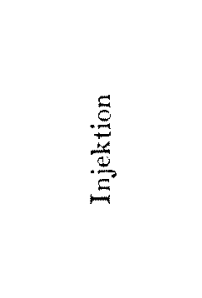 } & 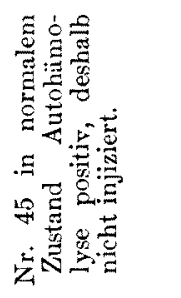 & 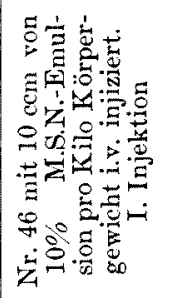 & 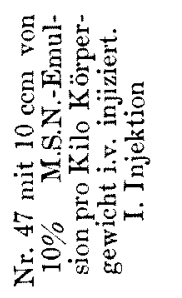 \\
\hline$\frac{5}{6 i}$ & 总 & 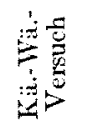 & to+1000 & 000000 & toooto \\
\hline \multirow[t]{2}{*}{ 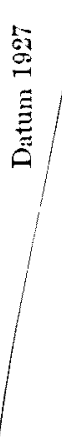 } & \multicolumn{2}{|c|}{ 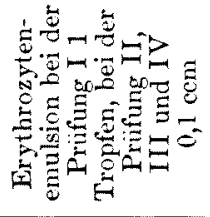 } & 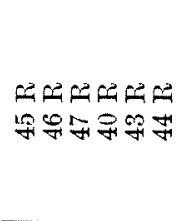 & 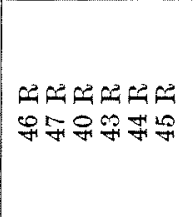 & 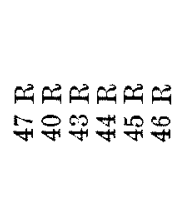 \\
\hline & \multicolumn{2}{|c|}{ 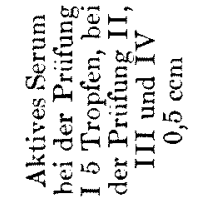 } & 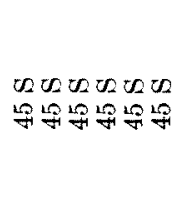 & 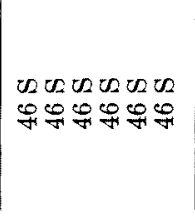 & 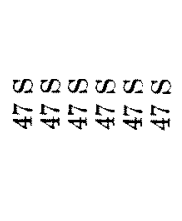 \\
\hline
\end{tabular}


Aus der Tabelle ersieht man, dass nur das Serum des normalen Kaninchens, Nr. 43, keinen Ambozeptor hat; dagegen haben alle Seren der andern injizierten Kaninchen Ambozeptoren. Es ist eiuleuchtend, dass es den roten Blutzellen von $\mathrm{Nr}$. 39, obgleich es injiziert wurde, an Rezeptoren völlig fehlt.

\section{Versuch 5 .}

Wir stellten an den Kombinationen von den Seren und roten Blutzellen mehrerer normaler und injizierter Kaninchen den Kälte-WürmeVersuch an, dann wurde den Kaninchen 10\% ige Meerschweinchennierenemulsion 2mal injiziert und der Verlauf der Autohämolyse der Kombinationen beobachtet.

Die Ergebnisse sind übersichtshalber in Tabelle VI zusammengefasst.

In der Tabelle sind Nr. 40 und 43 injizierte Kaninchen, Nr. 44, 45, 46 und 47 normale Kaninchen. Nr. 40 und 43 starben leider gleich nach der 1sten Injektion.

Aus diesem Versuch ist zu ersehen, dass durch die Injektion bei allen Kaninchen deutlich Ambozeptoren erzeugt wurden und bei den Kaninchen, die schon vor der Injektion Ambozeptoren besessen hatten, deren Gehalt zunahm.

Bei der Prüfung II in der Tabelle wurden die roten Blutzellen von Nr. 44 und 46, ebenso wie bei der Prüfung I, nicht aufgelöst. Das deutet darauf hin, dass durch die Injektion keine Rezeptoren erzengt wurden. Das Zustandekommen der Hämolyse bei den beiden eben erwähnten Blutzellen durch die Seren von Nr. 44 und 47 in der Prüfung III rührt möglicherweise davon her, dass die Ambozeptoren sich dabei bedeutend vermelirten und daher Autohämolyse auftrat, ungeachtet der wenigen Rezeptoren. Dass bei der Prüfung beide Blutzellen durch das Serum von Nr. 45 und 46, ganz wie bei den vorherigen Prüfungen, ungelöst blieben, deutet darauf hin, dass die Rezeptoren dabei nicht zunahmen.

A us den eben erwähnten Versuchsergebnissen lässt sich schliessen, dass die Entstehung der experimentellen Autohämolyse auf die Bildung von Autohämolysin im Serum von Kaninchen, deren rote Blutzellen von vornherein rezeptorenhaltig waren, zurückzufülıren ist. Die Rezeptoren werden durch die Injektion nicht beeinflusst. 


\section{Kapitel V.}

Sind das A utohamolysin und seine Rezeptoren beim Kaninchen pluralistisch oder unitarisch?

Nun ist die Frage, ob unser Autohämolysin, d. h. Ambozeptoren und Rezeptoren pluralistisch oder unitarisch sind. Zu ihrer Beantwortung stellten wir den nachstehenden Versuch an.

\section{Versuch 6.}

\section{(3. VI, 1927)}

Zunüchst wurden die Blutzellen von Nr. 38 mit jedem der Seren der drei injizierten Kaninchen, Nr. 38, 40 und 42 gemischt und an den Mischungen der Külte-Wärme-Versuch ausgeführt. Kaninchen Nr. 38, 40 und 42 wurde am 28. $\mathrm{V}$ ein Gemisch $10 \%$ iger Meerschweinchennierenemulsion und Hühnereigelb injiziert.

Die Ergebnisse zeigt Tabelle VII.

Tabelle VII.

\begin{tabular}{|c|c|c|c|}
\hline \multirow{2}{*}{$\begin{array}{c}\text { Aktives Serum } \\
0,5 \mathrm{~cm}\end{array}$} & \multirow{2}{*}{$\begin{array}{c}\text { Erythrozyten- } \\
\text { emulsion } \\
0,1 \mathrm{cem}\end{array}$} & \multicolumn{2}{|c|}{ Hämolyse } \\
\hline & & Kä.-Wï.-Versuch & Wä.-Versuch \\
\hline $\begin{array}{l}38 \mathrm{~S} \\
40 \mathrm{~S} \\
42 \mathrm{~S}\end{array}$ & $\begin{array}{l}38 \mathrm{R} \\
38 \mathrm{R} \\
38 \mathrm{R}\end{array}$ & $\begin{array}{c}+ \\
++ \\
+\end{array}$ & $\begin{array}{l}0 \\
0 \\
0\end{array}$ \\
\hline
\end{tabular}

Wie aus ihr ersichtlich, wurden die roten Blutzellen von Nr. 38 nicht allein durch ihr eigenes Serum, sondern auch durch das von Nr. 40 und 42 aufgelöst.

Darauf wurde 1,0 ccm des Serums von Nr. 38 mit 0,2 cem seiner eigenen roten Blutzellen gemischt, und daran wurde der Kälte-Wärme-Versuch angestellt. Natürlich fiel die Autohämolyse positiv aus. Sodann wurde es abzentrifugiert, das oben stehende hämolysierte Serum abgegossen, die niedergeschlagenen roten Blutzellen mit physiologischer Kochsalzlösung zweimal ausgewaschen und die Kochsalzlösung möglichst gut beseitigt. Die auf solche Weise erhaltene Emulsion der übrigbleibenden Erythrozyten wurde mit den Seren von Nr. 38, 40 und 42 gemischt und an ihnen der Kälte-Wärmc-Versuch angestellt. Die Ergebnisse sind in Tabelle VIII enthalten. 
Tabelle VIII.

\begin{tabular}{c|c|c|c}
\hline \multirow{2}{*}{ Aktives Serum } & $\begin{array}{c}\text { Emulsion der } \\
\text { ubriggebliebenen } \\
\text { Erythrozyten } \\
0,1 \mathrm{ccm}\end{array}$ & Kä.-Wü.-Versuch & Wä.-Versuch \\
\cline { 3 - 4 } $0,5 \mathrm{ccm}$ & $38 \mathbf{R}$ & 0 & 0 \\
\hline $38 \mathrm{~S}$ & $38 \mathrm{R}$ & 0 & 0 \\
$40 \mathrm{~S}$ & $38 \mathbf{R}$ & 0 & 0 \\
$42 \mathrm{~S}$ & & &
\end{tabular}

Man sieht daraus, dass die roten Blutzellen von Nr. 38 nicht allein durch ihr eigenes Serum, sondern auch durch das von Nr. 40 und 42 aufgelöst wurden. Wurden zunächst unter den roten Blutzellen von $\mathrm{Nr} .38$ die mit ihren eigenen Ambozeptoren beladenen ausgenommen und auf die übrig bleibenden Blutzellen wieder die Seren von Nr. 38, 40 und 42 einwirken lassen, so fiel die Autohämolyse bei jedem Serum ganz negativ aus.

Aus dem Versuch lässt sich schliessen, dass Rezeptoren und Ambozeptoren nicht pluralistisch, sondern unitarisch sind.

\section{Versuch 7.}

(3. VI, 1927)

In diesem Versuche ist die Versuchsanordnung ganz wie oben, nur mit der Änderung, dass Blutzellen normaler Kaninchen anstatt injizierter benutzt wurden.

Nr. 43 war ein rezeptorenhaltiges, normales Kaninchen ; Nr. 38, 40 und 42 waren, wie im Versuch 6 bemerkt, injizierte.

Gleich wie beim obigen Versuch liess man auf die Blutzellen von Nr. 43 die Seren von Nr. 38, 40 und 42 einwirken.

Das Ergebnis ist in Tabelle IX enthalten. Wie daraus ersichtlich, wurden die Blutzellen von Nr. 43 durch jedes der 3 Seren aufgelöst. Darauf wurde $1 \mathrm{cem}$ des Serums von Nr. 40 mit $0,2 \mathrm{ccm}$ der Blutzellen von Nr. 43 gemischt und an diesem Gemisch der Kälte-Wärme-Versuch ausgeführt.

Tabelle IX.

\begin{tabular}{c|c|c|c}
\hline \multirow{2}{*}{$\begin{array}{c}\text { Aktives Serum } \\
0,5 \mathrm{ccm}\end{array}$} & $\begin{array}{c}\text { Erythrozyten- } \\
\text { emulsion } \\
0,1 \mathrm{ccm}\end{array}$ & Kï.-Wü.-Versuch & Wii.-Versuch \\
\hline & $43 \mathrm{R}$ & + & 0 \\
$48 \mathrm{~S}$ & $43 \mathrm{R}$ & ++ & 0 \\
$42 \mathrm{~S}$ & $43 \mathrm{R}$ & + & 0
\end{tabular}


Dann wurde es abzentrifugiert, das oben stehende Serum abgegossen und die niedergeschlagenen Blutzellen, gleich wie beim obigen Versuch, mit physiologischer Kochsalzlösung ausgewaschen. Die so gewonnene Emulsion der übriggebliebenen roten Blutzellen wurde je mit dem Serum von Nr. 38, 40 und 42 gemischt und an diesen Mischungen nochmals der Kälte-Wärme-Versuch angestellt. Das Resultat ist aus Tabelle X erkenntlich.

Tabelle $\mathrm{X}$.

\begin{tabular}{c|c|c|c}
\hline \multirow{2}{*}{ Aktives Serum } & $\begin{array}{c}\text { Enulsion der } \\
\text { ubriggebliebenen } \\
\text { Erythrozyten } \\
0,1 \mathrm{ccm}\end{array}$ & Kä.-W:̈.-Versuch & Wä.-Versuch \\
\cline { 3 - 4 } $0,5 \mathrm{ccm}$ & $43 \mathrm{R}$ & 0 & 0 \\
$38 \mathrm{~S}$ & $43 \mathrm{R}$ & 0 & 0 \\
$40 \mathrm{~S}$ & $43 \mathrm{R}$ & 0 & 0 \\
$42 \mathrm{~S}$ & &
\end{tabular}

Unter den roten Blutzellen von Nr. 43 wurden die durch ihre eigenen Ambozeptoren gebundenen ausgeschieden und auf die übrigen Blutzellen das Serum von Nr. 38, 40 und 42 einwirken lassen. Dabei fiel die Antohämolyse bei jedem Serum ganz negativ aus.

Auf Grund dieses Versuchsergebnisses halten wir es für bewiesen, dass auch nach dem Versuch mit roten Blutzellen normaler Kaninchen Ambozeptoren und Rezeptoren einheitlich sind.

\section{Zusammenfassung.}

1. Bei Kaniuchen kann man durch Vorbehandlung mit einem Gemisch von Lecithin und Schweineserum experimentell Autohämolyse hervorrufen.

2. Es gibt zweierlei normale Kaninchenseren, das autohämolysinhaltige und das nicht-autohämolysinhaltige.

3. Es gibt zweierlei Kaninchen, das an den Erythrozyten rezeptorenhaltige und das nicht-rezeptorenhaltige.

4. Die Entstehung der experimentellen Autohämolyse ist auf die Bildung von Ambozeptoren infolge Injektion im Serum des Kaninchens, dessen rote Blutzellen von vorherein rezeptorenhaltig sind, zurückzuführen.

5. Die Ambozeptoren und Rezeptoren bei Autohämolyse des Kaninchens sind einheitlich. 


\section{Literatur.}

(1) Namba, Nihon Naika Gakkai Zasshi, 1924, 12, 321 ; Deutsch. med. Woch., 1925, 594 ; Tohoku Journ. Exp. Med., 1927, 9, 454.

(2) Namba u. Sun am i, Nihon Naika Gakkai Zasshi, 1927, 15, 539.

(3) Sachs, Klopstock u. Weil, Deutsch. med. Woch., 1925, 589.

(4) I to, Chûgai Iji Shimpô, 1926, Nr. 1112, 909.

(5) Donath u. Landsteiner, Centralbl. f. Bakt. 190S, 45, 205.

(6) K. Itoh, Nihon Naika Gakkai Zasshi, 1928, 16, 319 ; Okayama Igakkai Zasshi, 1928, 487 ; Okayama Igakkai Zasshi, 1928, 2409.

(7) Witebsky, Kl. Woch., 1928, 20.

(\$) Bïr ger, Zeitschr. f. experim. Pathol. u. Therapie, 1912, 10, 190. 